\title{
Cellular Restriction Factors of Feline Immunodeficiency Virus
}

\section{Jörg Zielonka ${ }^{1,2}$ and Carsten Münk ${ }^{1, *}$}

1 Clinic for Gastroenterology, Hepatology and Infectiology, Medical Faculty, Heinrich Heine University, Düsseldorf 40225, Germany; E-Mail: Joerg.zielonka@roche.com

2 Roche Glycart AG, Schlieren 8952, Switzerland

* Author to whom correspondence should be addressed;

E-Mail: Carsten.Muenk@med.uni-duesseldorf.de; Tel.: +49-221-8110887; Fax:+49-221-8115431.

Received: 15 August 2011; in revised form: 26 September 2011 / Accepted: 30 September 2011 /

Published: 21 October 2011

\begin{abstract}
Lentiviruses are known for their narrow cell- and species-tropisms, which are determined by cellular proteins whose absence or presence either support viral replication (dependency factors, cofactors) or inhibit viral replication (restriction factors). Similar to Human immunodeficiency virus type 1 (HIV-1), the cat lentivirus Feline immunodeficiency virus (FIV) is sensitive to recently discovered cellular restriction factors from non-host species that are able to stop viruses from replicating. Of particular importance are the cellular proteins APOBEC3, TRIM5 $\alpha$ and tetherin/BST-2. In general, lentiviruses counteract or escape their species' own variant of the restriction factor, but are targeted by the orthologous proteins of distantly related species. Most of the knowledge regarding lentiviral restriction factors has been obtained in the HIV-1 system; however, much less is known about their effects on other lentiviruses. We describe here the molecular mechanisms that explain how FIV maintains its replication in feline cells, but is largely prevented from cross-species infections by cellular restriction factors.
\end{abstract}

Keywords: FIV; antiviral; restriction factor; APOBEC3; TRIM5; tetherin

\section{Introduction}

In many species of Felidae, including the domestic cat, individuals may be infected with a unique strain of feline immunodeficiency virus (FIV), and a related virus is also found in African hyenas (for a review, see $[1,2])$. Viruses isolated from various felid species show monophyletic proviral sequences, 
which supports the idea that FIVs are not frequently transmitted between different felid species [2-4]. FIV was introduced into the existing felid lineages at several different times during evolution. A co-adaptation between FIV and Felidae is assumed to have occurred for at least 10,000 years, and possibly as much as a million years for some species [2,3]. In contrast, FIV infection of the domestic cat appears to be of more recent origin [2]. In addition, singular events of FIV felid-to-felid cross-species transmissions and repeated FIV transmissions from bobcats to pumas have been observed (for an overview, see [1,5,6]).

In mammals, including felids, the innate immune system provides a first line of defense against pathogens. Induction of type I interferon regulates the expression of several interferon-stimulated genes (ISGs) whose protein products have direct antiviral properties. A group of proteins with potent antiviral properties, known collectively as "restriction factors," are constitutively expressed in cells, but also induced by type I interferon. These proteins are able to limit replication by targeting specific steps in the viral life cycle [7]. However, lentiviruses have developed counteracting proteins to survive and replicate in their host mammal. While orthologous cellular proteins, which differ specifically in the interaction sites of the counteracting viral proteins, limit inter-species transfer, a high genetic variability in the restriction factors might also limit the spread and extent of infections and disease within the natural host population (intra-species transfer) [8].

FIV infection of felids shows substantial variation in disease outcome: in domestic cats, FIV can induce a strong immune pathology with a $\mathrm{T}$ cell depletion and immunodeficiency, resulting in opportunistic infections as well as weight loss and neurological disease (for review see [9,10]); however, in non-domestic felids infections with FIV appear to be apathogenic in most individuals [1]. For example, in FIV-infected lions and pumas, $\mathrm{T}$ cell depletion without disease has been described [11,12]. Interestingly, different subtypes of lion FIV may have different patterns of pathogenicity and transmissibility among African lions [13]. Some of these variations are likely influenced by differences in viral adaptation to the restriction factors of their hosts.

Much of today's knowledge of anti-lentiviral restriction factors is derived from the intensive characterization of the interaction of human immunodeficiency virus type 1 (HIV-1) with different host cells. However, recent investigations have also focused on how FIV escapes its host species' own restriction factors. Many of the accessory gene products of HIV-1 counteract cellular restriction factors. For example, the Vif protein inhibits APOBEC3 cytidine deaminases (see Section 2), while the Vpu protein protects HIV-1 from tetherin (see Section 4). Vpr inhibits a cellular factor that is still unidentified but, interestingly, $\mathrm{Vpx}$, which is closely related to $\mathrm{Vpr}$ (found, for example in Human immunodeficiency virus type 2, HIV-2) is a potent inhibitor of SAMHD1 (see Section 5). In contrast to HIV-1, FIV has only a vif gene and genes such as $v p r, v p x$ and $v p u$ are not present. Instead, a gene for the less well-characterized multifunctional protein OrfA (Orf-A, Orf-2) is uniquely found in FIV (see Section 6). A further restriction factor, TRIM5 $\alpha$, is not counteracted by accessory proteins. While all primate lentiviruses evolved in the presence of TRIM5 $\alpha$, the feline lentiviruses did not face this protein in their natural hosts because felids express a truncated, inactive variant of the TRIM5 protein (see Section 3) [14].

The strain-specific evolution of FIVs is likely driven by genetic differences in cellular dependency and restriction factors, in addition to selection by the immune system. We can assume that, besides differences in these factors, the FIV cross-species transfer from a felid to a felid/non-felid is also 
impaired by other limitations. Since FIV infection in domestic cats induces a fatal immunodeficiency that is very similar to AIDS in humans [9,10], FIV infection of cats not only provides a unique model to investigate the evolutionary role of restriction factors on cross-species transmission, but also virus evolution and its impact on AIDS induction.

\section{FIV and APOBEC3}

The mammalian APOBEC3 (A3; apolipoprotein B mRNA editing enzyme catalytic polypeptide 3) protein family was discovered through the study of the HIV-1 Vif. HIV-1 virions that are produced in permissive cells are able to infect permissive and non-permissive cells, whereas $\Delta v i f$ virons produced in non-permissive cells are unable to infect target cells $[15,16]$. These findings suggested the existence of a Vif-sensitive antiviral factor that was later identified as human APOBEC3G (Figure 1a) [17-19]. This interferon-inducible cellular factor is part of the AID/APOBEC gene family, which share a characteristic zinc (Z)-coordinating catalytic motif (His-X-Glu- $\mathrm{X}_{23-28}$-Pro-Cys- $\mathrm{X}_{2-4}-\mathrm{Cys}$ ) [20]. The A3 proteins can be classified according to the presence of a Z1, Z2 or Z3 motif (Figure 1b) [21-23]. A multiplicity of evolutionary events driven by host adaptation to viruses - including preservations, deletions, duplications, subfunctionalizations and neofunctionalizations - have led to a number of different forms of A3 genes within mammals [21,23]. Humans express seven A3 proteins (APOBEC3A, $-B,-C,-D,-F,-G$ and $-H$, Figure 1a) with either one or two zinc-coordinating domains that can inhibit various retroviruses, endogenous retroelements and DNA viruses [24-28].

Figure 1. Human and feline APOBEC3 (A3) proteins. (a) Schematic representation of human and feline A3 cytidine deaminases. All A3 proteins share at least one zinc $(Z)$-coordinating catalytic motif. The color code indicates the amino acid specificity of the different deaminase domains (Z1, Z2 and Z3). Humans express seven A3 proteins, $\mathrm{A} 3 \mathrm{~A}-\mathrm{A} 3 \mathrm{H}$; cats express four A3 proteins, A3Z2a-A3Z2-Z3. (b) Amino acid sequences of indicated domains. Group-specific distinctions of Z-domains are highlighted.

(a)

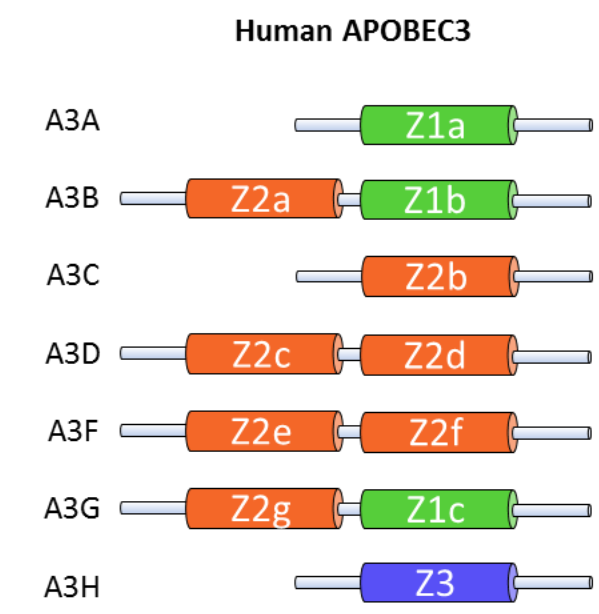

Feline APOBEC3

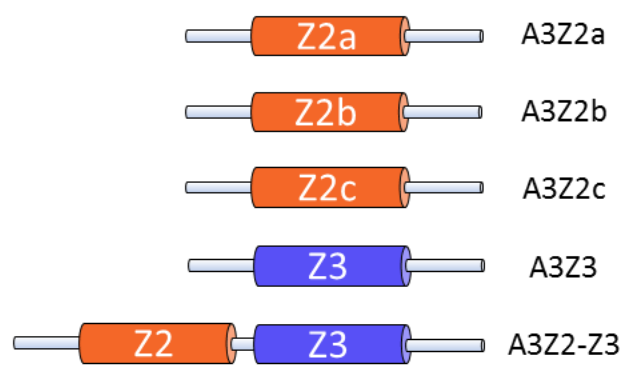

(b)

$21 x_{6-11} H x E x_{5} x x_{17} \quad S W \stackrel{s}{s} P C x_{2-4} C x_{6} F x_{8} L x_{5} R \mid Y x_{8-11} L x_{2} L x_{8} \quad x M x_{3-4}$

$22 x_{3-7} H x E x_{5} W F x_{16-20} S W \underset{T}{S} P C x_{2} \quad C x_{6} F x_{8} L x_{5} R L Y x_{8-11} L x_{2} L x_{8-12} x_{M} M x_{3-4}$

Z3 $x_{3-4} H x E x_{5} \quad x x_{14-17} T W S P C x_{2} \quad C x_{6} F x_{8} L x_{5} R L Y x_{10} L x_{2} L x_{8} \quad V M x_{3-4}$ 
In the domestic cat, there are three copies of a $\mathrm{Z} 2$ gene and a single copy of a $\mathrm{Z3}$ gene (Figure 1a) and are likely present in other feline species as well [23,29,30]. Besides these single-Z-domain proteins, Felidae express three very similar two-domain A3 proteins (Figure 1a, shown as a single A3Z2-Z3 protein for simplicity) by a complex process of read-through transcription and alternative splicing $[23,29,30]$. A feline A3 gene encoding a Z1 domain protein does not exist. In cats, the A3 genes are polymorphic and are under positive selection, indicating that they are relevant in the "arms race" between host and retrovirus [23].

The enzymatic activity of virion-encapsidated A3 results in the hydrolytic deamination of cytosine bases in the single-stranded viral (-) DNA that is synthesized during reverse transcription, leading to viral genome degradation, or to G-to-A hypermutations on the (+) DNA strand (Figure 2) [31-36]. However, A3 proteins also have deaminase-independent antiviral activities, and deaminase-deficient A3 mutants are still able to reduce accumulation of reverse transcription products [37-41]. The Vif protein of HIV-1 forms an interaction between A3 and a ubiquitin E3 ligase complex consisting of elongin $\mathrm{B}$ and $\mathrm{C}$, cullin5, and ring box-1 [42]; this interaction results in the A3 polyubiquitination that leads to proteasome-mediated degradation of the A3 protein [42-46]. In addition, Vif of HIV-1 inhibits A3 proteins by other non-degrading mechanisms (for a review, see [24]). Like HIV-1, FIV also encodes a Vif protein $[23,29,30,47]$. FIVs with an inactivated vif gene do not productively infect feline blood cells or show replication in cats [48-50].

Recent studies show that FIV Vif counteracts the feline A3 antiviral activity [23,29,30,47]. vif-deficient FIV is moderately inhibited by feline A3Z3 and is strongly suppressed by feline A3Z2-Z3, whereas wild-type virus infectivity is not influenced by feline A3 proteins [23,30]. Both FIV and FIV $\Delta$ vif are very sensitive to three of the seven human A3s (A3F, A3G and A3H) [23,30,47]. The antiviral activity of feline A3s against FIV $\Delta v i f$ correlated with the detection of cytidine deaminated, edited viral genomes [23]. Whether feline A3s also have non-editing antiviral activities has not yet been investigated. Further, it is unknown why feline A3Z2 proteins do not inhibit FIV $\Delta$ vif or FIV. However, the feline A3Z2 proteins are active cytidine deaminases and they restrict Bet-deficient Feline foamy virus. This feline retrovirus uses its accessory protein, Bet, to counteract the feline A3Z2 proteins via a degradation-independent pathway [23,51]. In contrast, expression of FIV Vif induces the degradation of feline A3s and thus prevents the encapsidation of A3s into FIV particles [29,30,47]. The degradation of feline A3 proteins by FIV Vif occurs efficiently in human cells indicating that this Vif activity does not depend on species-specific host factors [29,30,47]. It has not yet been shown but it is likely that FIV Vif recruits elongin B/C, cullin5, and ring box-1 in human cells as in feline cells to induce polyubiquitination of feline $\mathrm{A} 3 \mathrm{~s}$.

Vif proteins can be counteractive, non-active or semi-active against different A3 proteins. Surprisingly, the domestic cat FIV Vif protein can efficiently inhibit A3 restriction factors of three tested Felidae (puma, lion, lynx) and shows a reduced activity to A3s from the tiger [30]. These results indicate that most of the diverse felid A3s of big cats are probably not major determinants that prevent cross-species transmission of FIV from the domestic cat to these closely related animal species. In contrast, FIV Vif is completely inactive against A3 proteins from primates and other non-felid species $[23,30,47]$. A characterization of the molecular interaction of domestic cat FIV Vif with A3s of different felids may reveal the binding domains of Vif and A3; it may also explain the broad activity of domestic cat FIV Vif. 
Figure 2. Impact of the cellular restriction factors APOBEC3 (A3), TRIM5 $\alpha$ and tetherin on FIV replication. The FIV replication cycle starts by infection of either feline or non-feline cells and the resulting FIV particles then infect a target cell that shows no TRIM5 $\alpha$ restriction. FIV Vif targets the feline A3 protein for proteasomal degradation but it is inactive against A3 proteins from non-felid species (1). If Vif is not expressed or does not bind to $\mathrm{A} 3, \mathrm{~A} 3$ is packaged into FIV virions budding from the producer cells (2). During the next round of infection in target cells, encapsidated A3 proteins act as inhibitors of virus replication. Single-stranded viral DNA serves as a substrate for A3-induced cytidine deamination, causing hypermutations of the viral DNA, during which deoxycytidines are converted to deoxyuridines. Uracil-containing minus-strand DNA can be targeted by uracil DNA glycosylase, which could lead to endonucleolytic cleavage (3). The number of integrated, highly mutated proviruses is low. In non-feline cells, TRIM5 $\alpha$ restricts FIV soon after post-entry, likely by acceleration of the viral uncoating process. TRIM5 $\alpha$ may also promote innate immune signaling. The truncated feline TRIM5 $\alpha$ is incapable of restricting retroviruses (4). Feline tetherin is not able to restrict direct cell-to-cell spread of FIV, but can restrict the release of cell-free particles. A FIV antagonist (indicated by a question mark) of feline tetherin has not yet been detected. FIV is also inhibited by non-felid tetherin proteins (5). Many details of this model are based on experimental results of HIV-1 in primate cells.

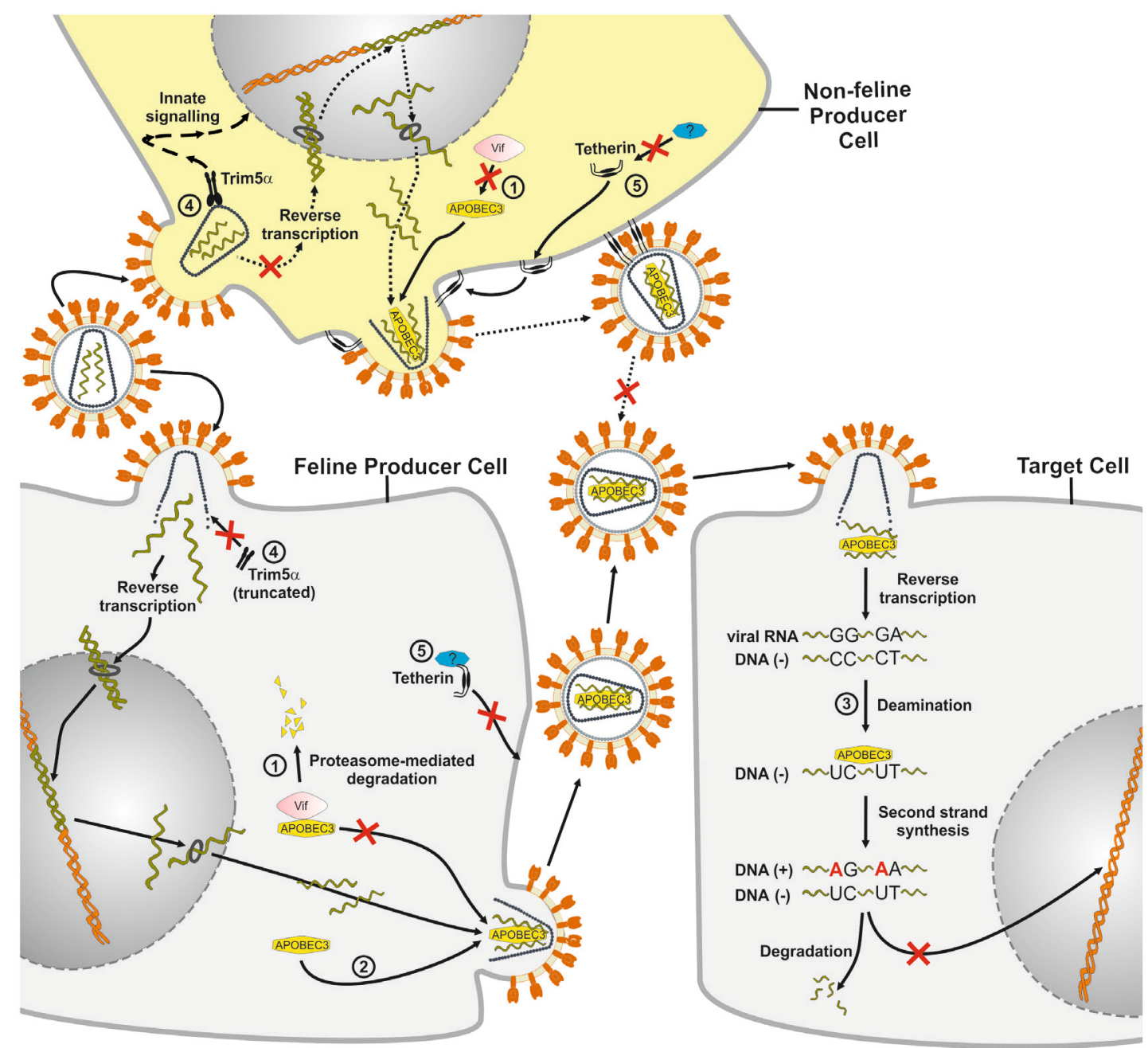




\section{FIV and TRIM5}

HIV replication in simian cells is blocked during uncoating at the early post-entry stage - a finding that was used to identify the restriction factor TRIM5 [52], which is constitutively expressed, but interferon treatment can further increase its levels [53]. TRIM5 $\alpha$ is a tripartite motif protein with a RING, B-box 2 and coiled-coil (CC) domain (RBCC), as well as a carboxy-terminal B30.2 (SPRY) domain (Figure 3a). The B30.2 domain of TRIM5a binds to the viral capsid of incoming viral particles, while the RBCC domains mediate the localization to cytoplasmic bodies and are important for TRIM5 $\alpha$ self-association [54-61]. TRIM5 $\alpha$ inhibits HIV-1 and other retroviruses in a species-specific manner. Thus retroviruses replicate in the presence of TRIM5 $\alpha$ proteins of their host species and are inhibited by orthologous TRIM5 $\alpha$ proteins. Species-adapted retroviruses evolved viral capsids that do not bind TRIM5 $\alpha$ proteins expressed in their host species [62]. Simian TRIM5 $\alpha$ likely acts at several levels: it restricts HIV-1 by accelerating the viral uncoating process, which leads to an inhibition of the reverse transcription (Figure 2) [63-65], and TRIM5 $\alpha$ also leads to an integration block that appears after the reverse transcription block is relieved by inhibition of the proteasome [66]. Insights into the multifunctional nature of TRIM5 $\alpha$ were obtained in a recent study by Pertel et al. that suggests that TRIM5 $\alpha$ is a pattern-recognition receptor for HIV-1 (Figure 2) [67]. TRIM5 $\alpha$ promotes innate immune signaling of the mitogen-activated protein kinase and NF- $\mathrm{KB}$ signaling pathways by its association with the retroviral capsid lattice and the E2 ubiquitin-conjugating enzyme complex UBC13-UEV1A that activates TAK1 kinase [67]. Furthermore, the authors demonstrated that TRIM5 $\alpha$ has a specific effect on the expression of NF- $\mathrm{KB}$ - and AP-1-responsive inflammatory chemokines and cytokines [67]. The knockdown of TRIM5 $\alpha$ in myeloid cells attenuates lipopolysaccharide (LPS)-induced immune signaling and also rescues viral infections from the LPS-induced antiviral gene expression [67]. Thus, TRIM5 $\alpha$ plays a role in LPS-triggered immune activation through the Toll-like receptor 4 pathway.

Human and rhesus macaque TRIM5 $\alpha$ can inhibit the infection of FIV if expressed in feline cells $[54,68]$. In single-round infection assays, it appears that the antiviral activity of the rhesus protein is stronger than that of human TRIM5 $\alpha$. Feline cells expressing human or rhesus TRIM5 $\alpha$ also potently block spreading replication of FIV without the appearance of revertants [68]. Most human cell lines, with the exception of HEK 293T, are not permissive for transduction by FIV vectors, especially $\mathrm{T}$ cell lines that show a strong restriction [68].

Owl monkeys and macaques express a protein called TRIMCyp due to a cDNA of the cyclophilin A (CypA) gene that retrotransposed into the 3' region of the TRIM5 gene [69-73]. In owl monkeys, the CypA cDNA is inserted into intron seven of the TRIM5 gene [71]. A distinct evolutionary origin of TRIMCyp is found in three macaque species (M. fascicularis, M. mulatta, and M. nemestrina) where the CypA cDNA retrotransposed in the $3^{\prime}$ untranslated region of the TRIM5 gene and macaque TRIMCyp is expressed by exon skipping from exon six to CypA [69,70,72,73]. Owl monkey as well macaque TRIMCyps consist of the RBCC domains of TRIM5 fused with a carboxy-terminal CypA moiety (Figure 3b) [69-74]. CypA binds the surface of the capsid proteins of HIV-1 and FIV that form the viral core [75-78]. In FIV, the interaction of CypA can be prevented by a P90A mutation in the loop between helix 4 and 5 of the capsid [75,78]. TRIMCyp of Owl monkeys and macaques, or an artificial human TRIMCyp, restricts infection with FIV [54,72,73,78-82]. Similar to TRIM5 $\alpha$, treating 
rhesus TRIMCyp-expressing feline cells with a proteasome inhibitor relieves the block in the reverse transcription of FIV, but does not restore the capacity of FIV to transduce these cells [73].

McEwan et al. discovered that Feliformia express a truncated TRIM5 gene, which explains why feline cells do not show a TRIM5-typical restriction to retroviruses (Figure 2) [14]. The feline mRNA of TRIM5 contains a premature stop codon expressing a RBCC protein without the B30.2 domain (Figure 3a). In cats, the missing B30.2 domain is not replaced by CypA as seen in some monkeys [14]. The truncated feline TRIM5 appears to be without any antiretroviral activity as overexpression of the feline TRIM5 does not prevent infection with murine leukemia virus, HIV-1 or a simian immunodeficiency virus (SIV) of macaques (SIVmac) [14]. However, it is possible that the truncated feline TRIM5 protein is similar to the human TRIM5 $\alpha$ involved in LPS-mediated signaling [67], potentially explaining why this gene is retained in Feliformia. Interestingly, a synthetic fusion of the feline TRIM5 to the feline CypA (Figure 3b) generated a potent inhibitor of FIV and HIV-1 [75,83]. These results show that the RBCC domains of feline TRIM5 retain their intrinsic antiviral function.

Figure 3. Domain structure of TRIM5 $\alpha$ and TRIMCyp proteins. (a) TRIM5 $\alpha$ is defined by four domains: RING finger, B-box 2, coiled-coil and B30.2. The feline TRIM5 $\alpha$ lacks the B30.2 capsid-binding domain because of a premature stop codon in the mRNA transcript. (b) In some monkeys, TRIMCyp is expressed, in which the B30.2 domain of TRIM5 $\alpha$ is replaced with a cyclophilin A (CypA) domain. Expression of feline TRIMCyp was not observed. Dietrich et al. produced a synthetic feline TRIMCyp by fusion of the truncated TRIM5 $\alpha$ and feline cyclophilin A [75].

(a)

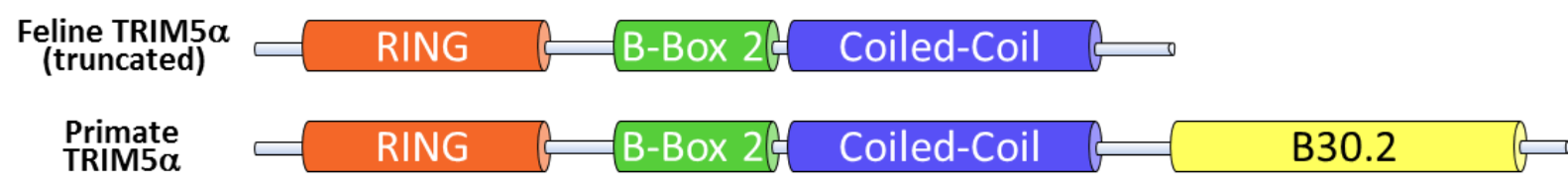

(b)

Feline TRIMCyp
$\begin{aligned} & \text { Primate } \\ & \text { TRIMCyp }\end{aligned}$ RING CypA
RING

\section{FIV and Tetherin}

The restriction factor tetherin (also known as CD317 or BST-2 or HM1.24), was identified by analyzing the cell type-specific particle release block of HIV-1 deficient for the viral protein $\mathrm{Vpu}[84,85]$. Tetherin is an interferon-induced protein that "tethers" HIV-1 $\Delta v p u$ particles at the cell surface (Figure 2). The Vpu protein of HIV-1 interferes with the cell surface expression of human tetherin in part by inducing its degradation [86,87]. Primate lentiviruses that lack a $v p u$ gene use either their Nef or Env proteins to counteract tetherin in the host cells (for review see [88-90]). In general, 
the lentiviral proteins that counteract are only active against tetherin proteins of their own host species. In addition to retroviruses, tetherin proteins are also inhibitory to herpesviruses, arenaviruses, filoviruses, rhabdoviruses, orthomyxoviruses and paramyxoviruses [91-98].

Tetherin is an unusual type II integral membrane protein (Figure 4) with an N-terminal transmembrane domain, an extracellular CC domain and a C-terminal glycosylphospatidylinositol (GPI) lipid anchor at its C-terminus [99]. Recent data indicate that the GPI anchor motif functions as a second transmembrane motif [100]. In humans, tetherin is expressed on several specialized cell types such as hepatocytes, monocytes, epithelial cells, terminally differentiated B cells and bone marrow stromal cells. It is upregulated in many cell types upon treatment with interferon [101]. The feline tetherin protein was recently cloned and functionally characterized [83,102]. Similar to human and mouse tetherin, the expression of feline tetherin is inducible by interferons but a detailed tissue expression pattern has not yet been determined [83,102]. In a transient co-expression system, feline tetherin is a potent inhibitor for the release of FIV and HIV-1 particles [83]. The release of FIV virus-like particles and wild-type particles is also strongly inhibited by the human tetherin $[83,91]$. Apparently, under such experimental conditions, FIV has no viral determinant that inhibits the antiviral activity of feline tetherin. In contrast to transient expression of tetherin, stably expressing feline tetherin in feline CrFK cells did not restrict virus spread of FIV (human tetherin was not tested) [83]. Similarly, in the HIV-1 system, the cell-to-cell transfer of $v p u$-deficient HIV-1 in T cells was not inhibited by human tetherin [103], although, contrasting results have also been reported [104]. This might indicate that Vpu of HIV-1 is not strongly required for viral spread in vivo. Support of this model comes from the observation, that in contrast to Vpu of HIV-1 pandemic group M, the Vpus of non-pandemic AIDS inducing HIV-1 groups $\mathrm{O}$ and $\mathrm{N}$ show no, or very low activity, against human tetherin [105]. These findings potentially explain why HIV-1 group $\mathrm{O}$ and $\mathrm{N}$ viruses propagate less efficiently in the human population than the pandemic HIV-1 group M virus. Together, these data indicate that FIV, in contrast to HIV-1, is transmitted mainly as a cell-associated virus and not as a cell-free virus.

Figure 4. Schematic structure of feline and human tetherin. Tetherins from both species share their principal elements: Cytoplasmatic (Cyto)-, transmembrane (TM)-, coiled-coiland glycophosphatidyl-inositol (GPI)-anchor domains.

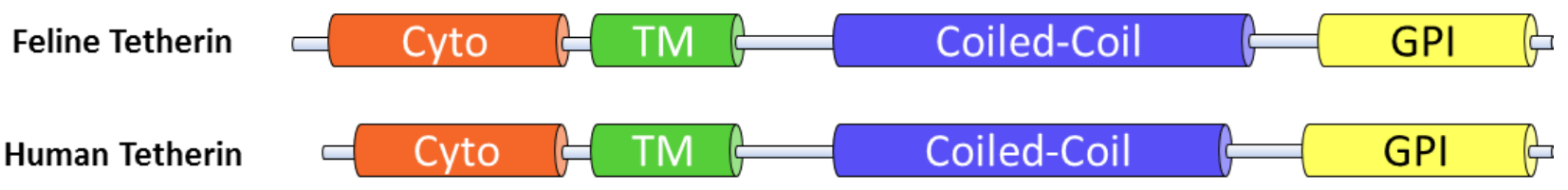

\section{FIV and SAMHD1}

Human cells of the myeloid lineage such as blood monocytes or monocyte-derived dendritic cells (mDCs), are highly refractory to infection by HIV-1 due to a post-entry restriction [106-111]. Some primate lentiviruses, such as SIV endemic to sooty mangabeys (SIVsm), SIVmac and HIV-2, do not show this replication restriction (for a review, see [112]). Human and feline mDCs also show a 
resistance against the productive infection with FIV [113-115]. In contrast to HIV-1, lentiviruses such as SIVsm/SIVmac/HIV-2 express an accessory protein called Vpx that is specifically encapsidated into viral particles [116,117]. Loss of Vpx expression in SIVmac and HIV-2 has no effect on the viral replication in established cell lines, but Vpx mutants show a delayed replication in cultures of PBMCs (peripheral blood mononuclear cells) and a replication block in macrophages [118-120]. In vivo, SIVsm (isolate $\mathrm{PBj}$ ) needs $\mathrm{Vpx}$ expression for efficient dissemination and the acute, unique pathogenesis of SIVsmPBj [121]. In infected monkeys, SIVmac Vpx mutants show a lower viremia, a delayed CD4 cell decline and a later AIDS induction compared to wild type viruses [122]. Thus, a Vpx-function for AIDS induction by SIVmac is not required and it is unclear why only some lentiviruses encode $\mathrm{Vpx}$ and infect mDCs.

In myeloid cells, Vpx mutants of HIV-2 and SIVmac show a post-entry block at reverse transcription or uncoating [115,123-125]. The Vpx protein forms a cullin 4-based E3 ubiquitin ligase complex (for a review, see [112]) indicating that, similar to Vif, Vpx acts as a substrate receptor to induce the degradation of a cellular protein. Recently, the human protein SAMHD1 was identified to be causative for the post-entry restriction of HIV-1 in myeloid cells [126,127]. Viral particle-associated Vpx protein induces a proteasome-dependent degradation of SAMHD1 in the target cell very early after entry $[126,127]$. The SAMHD1 protein has two domains that are widely found in all genomes: an N-terminal SAM domain followed by a HD domain (Figure 5). SAM (sterile $\alpha$ motif) domains have diverse functions, such as binding to kinases, other proteins or RNA [128]. The HD domain with histidine and aspartic acid residues for metal coordination defines a superfamily of metal-dependent phosphohydrolases, which includes many proteins that are involved in nucleic acid metabolism such as dGTPases, nucleotidyltransferases and helicases [129]. Mutations in the SAMHD1 gene lead to Aicardi-Goutieres syndrome, which includes cerebral atrophy, leukoencephalopathy, hepatosplenomegaly, and increased production of $\alpha$-interferon [130]. The antiviral mechanism of SAMHD1 is not yet identified but, based on the activities of proteins that share homology with SAMHD1, it is likely that SAMHD1 acts either as a nuclease that destroys the viral genetic material of incoming viruses, or functions as a sensor (or sensor-associated protein) that induces antiviral proteins. It would be interesting to determine whether the feline gene for SAMHD1 (found on cat chromosome A3) encodes an antiviral protein, and whether FIV expresses a viral counteracting factor against feline SAMHD1 that functions similarly to Vpx.

Figure 5. Schematic representation of the human SAMHD1 protein indicating the SAM and the HD domain. A putative feline SAMHD1-encoding gene is found on cat chromosome 13 .

Human SAMHD1

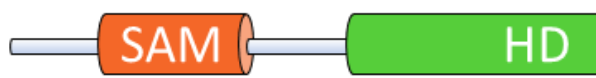

\section{Major Challenges in Research on FIV Restriction Factors}

The HIV-1 origin in humans is one of best studied lentiviral cross-species transmissions [131]. Because of the very high genome sequence identity between the two Hominidae, Pan troglodytes and 
Homo sapiens, it is not surprising that SIV of chimpanzees (SIVcpz) quickly adapted and developed a pandemic distribution once introduced in the human population. However, the evolution of HIV-2, derived from a SIV endemic to sooty mangabeys (SIVsm) demonstrates that lentiviruses can also rapidly cross between species in different families, in that case from Cercopithecidae to Hominidae $[132,133]$. FIV cross-species transfers are described so far only in Felidae, and mostly as singular events, with the exception of repeated transmissions of FIVs from bobcats to pumas $[1,5,6]$. It is unknown what the impact of restriction factors versus the relevance of other factors are in these cross-species transmissions [2]. There is a need for more field and laboratory studies that quantitate the potential of molecularly defined feline lentiviruses to establish cross-felid infections. It would be interesting to learn whether these cross-species transmitted viruses replicate in vivo to similar levels, with similar tissue distributions as the species-adapted FIVs, and whether they are rapidly controlled by the innate and/or adaptive immune system of the cat. Even for regular FIV infections in the domestic cat, information on the importance of cellular restriction factors is limited. Modern methods to knock-down the expression of genes or genetically modify FIV target cells with novel restriction factors (to model human HIV-1 gene therapy) will be useful in gaining further insights into the evolutionary potential of viral adaptation or its intrinsic constraints, the stability of viral genes and genomes, and the impact of restriction factors on the health of infected animals. A recent breakthrough is the generation of rhesus TRIMCyp transgenic cats [82]. PBMCs of theses transgenic animals expressed variable amounts of rhesus TRIMCyp and showed a partial resistance to FIV replication [82].

Besides the impact of known restriction factors on FIV replication and their use in therapeutic models, FIV has not been utilized in a systematic search for antiviral proteins and dependency factors. The recent identification of novel restriction factors that are counteracted by accessory proteins of HIV-1 raises the question as to whether FIV might also be used to identify novel cellular restriction factors. In this regard, it might be interesting to note that FIV encodes the protein OrfA, whose function is still enigmatic [134,135]. OrfA does not counteract of feline tetherin [83], but is important for replication in vivo and in primary $\mathrm{T}$ cells, and its exact role in FIV biology is not yet established. Different studies describe various functions of OrfA including: transactivating viral transcription, regulating the infectivity of FIV particles, inducing G2 cell cycle arrest, and downregulating the FIV receptor CD134 [136-139].

The induction of interferon following FIV infection of feline PBMCs and cats suggests that pattern-recognition receptors in hematopoietic cells detect the FIV infection [140]. How FIV or other lentiviruses are sensed, whether FIV has evolved partial escape mechanisms of this detection, and which feline ISGs show anti-FIV activity need much more investigation. A systematic analysis of all ISGs with FIV and FIV deleted in specific genes could identify factors that are antiviral and are counteracted by FIV's proteins. In human cells, many interaction partners of A3G, TRIM5 $\alpha$, tetherin and SAMHD1, and of HIV-1 accessory proteins, have been described or will be published soon (e.g., [42,67,141-143]). Thus, systems biology approaches for FIV and feline cells will be important to learn about the conserved and differing pathways used by HIV-1 and FIV. It may also allow us to better utilize the FIV cat model to discover novel treatment and healing options for HIV-1-infected patients. 


\section{Acknowledgments}

We thank Eric Logue for critically reading the manuscript. We thank Dieter Häussinger for constant support. C.M. is supported by the Heinz Ansmann Foundation for AIDS research.

\section{Conflict of Interest}

The authors declare no conflict of interest.

\section{References and Notes}

1. VandeWoude, S.; Apetrei, C. Going wild: Lessons from naturally occurring T-lymphotropic lentiviruses. Clin. Microbiol. Rev. 2006, 19, 728-762.

2. Pecon-Slattery, J.; Troyer, J.L.; Johnson, W.E.; O'Brien, S.J. Evolution of feline immunodeficiency virus in Felidae: Implications for human health and wildlife ecology. Vet. Immunol. Immunopathol. 2008, 123, 32-44.

3. Troyer, J.L.; Pecon-Slattery, J.; Roelke, M.E.; Johnson, W.; VandeWoude, S.; Vazquez-Salat, N.; Brown, M.; Frank, L.; Woodroffe, R.; Winterbach, C.; et al. Seroprevalence and genomic divergence of circulating strains of feline immunodeficiency virus among Felidae and Hyaenidae species. J. Virol. 2005, 79, 8282-8294.

4. Antunes, A.; Troyer, J.L.; Roelke, M.E.; Pecon-Slattery, J.; Packer, C.; Winterbach, C.; Winterbach, H.; Hemson, G.; Frank, L.; Stander, P.; et al. The evolutionary dynamics of the lion Panthera leo revealed by host and viral population genomics. PLoS Genet. 2008, 4, e1000251.

5. Troyer, J.L.; VandeWoude, S.; Pecon-Slattery, J.; McIntosh, C.; Franklin, S.; Antunes, A.; Johnson, W.; O'Brien, S.J. FIV cross-species transmission: An evolutionary prospective. Vet. Immunol. Immunopathol. 2008, 123, 159-166.

6. VandeWoude, S.; Troyer, J.; Poss, M. Restrictions to cross-species transmission of lentiviral infection gleaned from studies of FIV. Vet. Immunol. Immunopathol. 2010, 134, 25-32.

7. Wolf, D.; Goff, S.P. Host restriction factors blocking retroviral replication. Annu. Rev. Genet. 2008, 42, 143-163.

8. Meyerson, N.R.; Sawyer, S.L. Two-stepping through time: Mammals and viruses. Trends Microbiol. 2011, 19, 286-294.

9. Bendinelli, M.; Pistello, M.; Lombardi, S.; Poli, A.; Garzelli, C.; Matteucci, D.; Ceccherini-Nelli, L.; Malvaldi, G.; Tozzini, F. Feline immunodeficiency virus: An interesting model for AIDS studies and an important cat pathogen. Clin. Microbiol. Rev. 1995, 8, 87-112.

10. Hartmann, K. Clinical aspects of feline immunodeficiency and feline leukemia virus infection. Vet. Immunol. Immunopathol. 2011, 143, 190-201.

11. Roelke, M.E.; Pecon-Slattery, J.; Taylor, S.; Citino, S.; Brown, E.; Packer, C.; VandeWoude, S.; O'Brien, S.J. T-lymphocyte profiles in FIV-infected wild lions and pumas reveal CD4 depletion. J. Wildl. Dis. 2006, 42, 234-248.

12. Bull, M.E.; Kennedy-Stoskopf, S.; Levine, J.F.; Loomis, M.; Gebhard, D.G.; Tompkins, W.A. Evaluation of $\mathrm{T}$ lymphocytes in captive african lions (Panthera leo) infected with feline immunodeficiency virus. Am. J. Vet. Res. 2003, 64, 1293-1300. 
13. Troyer, J.L.; Roelke, M.E.; Jespersen, J.M.; Baggett, N.; Buckley-Beason, V.; Macnulty, D.; Craft, M.; Packer, C.; Pecon-Slattery, J.; O'Brien, S.J. FIV diversity: FIV(Ple) subtype composition may influence disease outcome in African lions. Vet. Immunol. Immunopathol. 2011, 143, 338-346.

14. McEwan, W.A.; Schaller, T.; Ylinen, L.M.; Hosie, M.J.; Towers, G.J.; Willett, B.J. Truncation of TRIM5 in the Feliformia explains the absence of retroviral restriction in cells of the domestic cat. J. Virol. 2009, 83, 8270-8275.

15. Gabuzda, D.H.; Lawrence, K.; Langhoff, E.; Terwilliger, E.; Dorfman, T.; Haseltine, W.A.; Sodroski, J. Role of vif in replication of human immunodeficiency virus type 1 in CD4+ T lymphocytes. J. Virol. 1992, 66, 6489-6495.

16. Sakai, H.; Shibata, R.; Sakuragi, J.; Sakuragi, S.; Kawamura, M.; Adachi, A. Cell-dependent requirement of human immunodeficiency virus type 1 Vif protein for maturation of virus particles. J. Virol. 1993, 67, 1663-1666.

17. Madani, N.; Kabat, D. An endogenous inhibitor of human immunodeficiency virus in human lymphocytes is overcome by the viral Vif protein. J. Virol. 1998, 72, 10251-10255.

18. Sheehy, A.M.; Gaddis, N.C.; Choi, J.D.; Malim, M.H. Isolation of a human gene that inhibits HIV-1 infection and is suppressed by the viral Vif protein. Nature 2002, 418, 646-650.

19. Simon, J.H.; Gaddis, N.C.; Fouchier, R.A.; Malim, M.H. Evidence for a newly discovered cellular anti-HIV-1 phenotype. Nat. Med. 1998, 4, 1397-1400.

20. Jarmuz, A.; Chester, A.; Bayliss, J.; Gisbourne, J.; Dunham, I.; Scott, J.; Navaratnam, N. An anthropoid-specific locus of orphan C to U RNA-editing enzymes on chromosome 22. Genomics 2002, 79, 285-296.

21. LaRue, R.S.; Jonsson, S.R.; Silverstein, K.A.; Lajoie, M.; Bertrand, D.; El-Mabrouk, N.; Hotzel, I.; Andresdottir, V.; Smith, T.P.; Harris, R.S. The artiodactyl APOBEC3 innate immune repertoire shows evidence for a multi-functional domain organization that existed in the ancestor of placental mammals. BMC Mol. Biol. 2008, 9, 104.

22. LaRue, R.S.; Andresdottir, V.; Blanchard, Y.; Conticello, S.G.; Derse, D.; Emerman, M.; Greene, W.C.; Jonsson, S.R.; Landau, N.R.; Löchelt, M.; et al. Guidelines for naming nonprimate APOBEC3 genes and proteins. J. Virol. 2009, 83, 494-497.

23. Münk, C.; Beck, T.; Zielonka, J.; Hotz-Wagenblatt, A.; Chareza, S.; Battenberg, M.; Thielebein, J.; Cichutek, K.; Bravo, I.G.; O'Brien, S.J.; et al. Functions, structure, and read-through alternative splicing of feline APOBEC3 genes. Genome Biol. 2008, 9, R48.

24. Chiu, Y.L.; Greene, W.C. The APOBEC3 cytidine deaminases: An innate defensive network opposing exogenous retroviruses and endogenous retroelements. Annu. Rev. Immunol. 2008, 26, 317-353.

25. Narvaiza, I.; Linfesty, D.C.; Greener, B.N.; Hakata, Y.; Pintel, D.J.; Logue, E.; Landau, N.R.; Weitzman, M.D. Deaminase-independent inhibition of parvoviruses by the APOBEC3A cytidine deaminase. PLoS Pathog. 2009, 5, e1000439.

26. Suspene, R.; Aynaud, M.M.; Koch, S.; Pasdeloup, D.; Labetoulle, M.; Gaertner, B.; Vartanian, J.P.; Meyerhans, A.; Wain-Hobson, S. Genetic editing of herpes simplex virus 1 and Epstein-Barr herpesvirus genomes by human APOBEC3 cytidine deaminases in culture and in vivo. J. Virol. 2011, 85, 7594-7602. 
27. Vartanian, J.P.; Guetard, D.; Henry, M.; Wain-Hobson, S. Evidence for editing of human papillomavirus DNA by APOBEC3 in benign and precancerous lesions. Science 2008, 320, 230-233.

28. Muckenfuss, H.; Hamdorf, M.; Held, U.; Perkovic, M.; Löwer, J.; Cichutek, K.; Flory, E.; Schumann, G.G.; Münk, C. APOBEC3 proteins inhibit human LINE-1 retrotransposition. J. Biol. Chem. 2006, 281, 22161-22172.

29. Stern, M.A.; Hu, C.; Saenz, D.T.; Fadel, H.J.; Sims, O.; Peretz, M.; Poeschla, E.M. Productive replication of Vif-chimeric HIV-1 in feline cells. J. Virol. 2010, 84, 7378-7395.

30. Zielonka, J.; Marino, D.; Hofmann, H.; Yuhki, N.; Löchelt, M.; Münk, C. Vif of feline immunodeficiency virus from domestic cats protects against APOBEC3 restriction factors from many felids. J. Virol. 2010, 84, 7312-7324.

31. Bishop, K.N.; Holmes, R.K.; Sheehy, A.M.; Davidson, N.O.; Cho, S.J.; Malim, M.H. Cytidine deamination of retroviral DNA by diverse APOBEC proteins. Curr. Biol. 2004, 14, 1392-1396.

32. Harris, R.S.; Bishop, K.N.; Sheehy, A.M.; Craig, H.M.; Petersen-Mahrt, S.K.; Watt, I.N.; Neuberger, M.S.; Malim, M.H. DNA deamination mediates innate immunity to retroviral infection. Cell 2003, 113, 803-809.

33. Lecossier, D.; Bouchonnet, F.; Clavel, F.; Hance, A.J. Hypermutation of HIV-1 DNA in the absence of the Vif protein. Science 2003, 300, 1112.

34. Mangeat, B.; Turelli, P.; Caron, G.; Friedli, M.; Perrin, L.; Trono, D. Broad antiretroviral defence by human APOBEC3G through lethal editing of nascent reverse transcripts. Nature 2003, 424, 99-103.

35. Mariani, R.; Chen, D.; Schröfelbauer, B.; Navarro, F.; König, R.; Bollman, B.; Münk, C.; Nymark-McMahon, H.; Landau, N.R. Species-specific exclusion of APOBEC3G from HIV-1 virions by Vif. Cell 2003, 114, 21-31.

36. Zhang, H.; Yang, B.; Pomerantz, R.J.; Zhang, C.; Arunachalam, S.C.; Gao, L. The cytidine deaminase CEM15 induces hypermutation in newly synthesized HIV-1 DNA. Nature 2003, 424, 94-98.

37. Mbisa, J.L.; Barr, R.; Thomas, J.A.; Vandegraaff, N.; Dorweiler, I.J.; Svarovskaia, E.S.; Brown, W.L.; Mansky, L.M.; Gorelick, R.J.; Harris, R.S.; et al. Human immunodeficiency virus type 1 cDNAs produced in the presence of APOBEC3G exhibit defects in plus-strand DNA transfer and integration. J. Virol. 2007, 81, 7099-7110.

38. Newman, E.N.; Holmes, R.K.; Craig, H.M.; Klein, K.C.; Lingappa, J.R.; Malim, M.H.; Sheehy, A.M. Antiviral function of APOBEC3G can be dissociated from cytidine deaminase activity. Curr. Biol. 2005, 15, 166-170.

39. Iwatani, Y.; Chan, D.S.; Wang, F.; Maynard, K.S.; Sugiura, W.; Gronenborn, A.M.; Rouzina, I.; Williams, M.C.; Musier-Forsyth, K.; Levin, J.G. Deaminase-independent inhibition of HIV-1 reverse transcription by APOBEC3G. Nucleic Acids Res. 2007, 35, 7096-7108.

40. Bishop, K.N.; Holmes, R.K.; Malim, M.H. Antiviral potency of APOBEC proteins does not correlate with cytidine deamination. J. Virol. 2006, 80, 8450-8458.

41. Holmes, R.K.; Koning, F.A.; Bishop, K.N.; Malim, M.H. APOBEC3F can inhibit the accumulation of HIV-1 reverse transcription products in the absence of hypermutation. Comparisons with APOBEC3G. J. Biol. Chem. 2007, 282, 2587-2595. 
42. Yu, X.; Yu, Y.; Liu, B.; Luo, K.; Kong, W.; Mao, P.; Yu, X.F. Induction of APOBEC3G ubiquitination and degradation by an HIV-1 Vif-Cul5-SCF complex. Science 2003, 302, 1056-1060.

43. Conticello, S.G.; Harris, R.S.; Neuberger, M.S. The Vif protein of HIV triggers degradation of the human antiretroviral DNA deaminase APOBEC3G. Curr. Biol. 2003, 13, 2009-2013.

44. Marin, M.; Rose, K.M.; Kozak, S.L.; Kabat, D. HIV-1 Vif protein binds the editing enzyme APOBEC3G and induces its degradation. Nat. Med. 2003, 9, 1398-1403.

45. Mehle, A.; Strack, B.; Ancuta, P.; Zhang, C.; McPike, M.; Gabuzda, D. Vif overcomes the innate antiviral activity of APOBEC3G by promoting its degradation in the ubiquitin-proteasome pathway. J. Biol. Chem. 2004, 279, 7792-7798.

46. Sheehy, A.M.; Gaddis, N.C.; Malim, M.H. The antiretroviral enzyme APOBEC3G is degraded by the proteasome in response to HIV-1 Vif. Nat. Med. 2003, 9, 1404-1407.

47. LaRue, R.S.; Lengyel, J.; Jonsson, S.R.; Andresdottir, V.; Harris, R.S. Lentiviral Vif degrades the APOBEC3Z3/APOBEC3H protein of its mammalian host and is capable of cross-species activity. J. Virol. 2010, 84, 8193-8201.

48. Lockridge, K.M.; Himathongkham, S.; Sawai, E.T.; Chienand, M.; Sparger, E.E. The feline immunodeficiency virus vif gene is required for productive infection of feline peripheral blood mononuclear cells and monocyte-derived macrophages. Virology 1999, 261, 25-30.

49. Shen, X.; Leutenegger, C.M.; Stefano, C.K.; Pedersen, N.C.; Sparger, E.E. A feline immunodeficiency virus vif-deletion mutant remains attenuated upon infection of newborn kittens. J. Gen. Virol. 2007, 88, 2793-2799.

50. Inoshima, Y.; Miyazawa, T.; Mikami, T. The roles of vif and ORF-A genes and AP-1 binding site in in vivo replication of feline immunodeficiency virus. Arch. Virol. 1998, 143, 789-795.

51. Löchelt, M.; Romen, F.; Bastone, P.; Muckenfuss, H.; Kirchner, N.; Kim, Y.B.; Truyen, U.; Rosler, U.; Battenberg, M.; Saib, A.; et al. The antiretroviral activity of APOBEC3 is inhibited by the foamy virus accessory Bet protein. Proc. Natl. Acad. Sci. U. S. A. 2005, 102, 7982-7987.

52. Stremlau, M.; Owens, C.M.; Perron, M.J.; Kiessling, M.; Autissier, P.; Sodroski, J. The cytoplasmic body component TRIM5alpha restricts HIV-1 infection in Old World monkeys. Nature 2004, 427, 848-853.

53. Carthagena, L.; Bergamaschi, A.; Luna, J.M.; David, A.; Uchil, P.D.; Margottin-Goguet, F.; Mothes, W.; Hazan, U.; Transy, C.; Pancino, G.; et al. Human TRIM gene expression in response to interferons. PLoS One 2009, 4, e4894.

54. Diaz-Griffero, F.; Kar, A.; Lee, M.; Stremlau, M.; Poeschla, E.; Sodroski, J. Comparative requirements for the restriction of retrovirus infection by TRIM5alpha and TRIMCyp. Virology 2007, 369, 400-410.

55. Diaz-Griffero, F.; Qin, X.R.; Hayashi, F.; Kigawa, T.; Finzi, A.; Sarnak, Z.; Lienlaf, M.; Yokoyama, S.; Sodroski, J. A B-box 2 surface patch important for TRIM5alpha self-association, capsid binding avidity, and retrovirus restriction. J. Virol. 2009, 83, 10737-10751.

56. Javanbakht, H.; Diaz-Griffero, F.; Stremlau, M.; Si, Z.; Sodroski, J. The contribution of RING and B-box 2 domains to retroviral restriction mediated by monkey TRIM5alpha. J. Biol. Chem. 2005, 280, 26933-26940. 
57. Li, X.; Sodroski, J. The TRIM5alpha B-box 2 domain promotes cooperative binding to the retroviral capsid by mediating higher-order self-association. J. Virol. 2008, 82, 11495-11502.

58. Ohkura, S.; Yap, M.W.; Sheldon, T.; Stoye, J.P. All three variable regions of the TRIM5alpha B30.2 domain can contribute to the specificity of retrovirus restriction. J. Virol. 2006, 80, 8554-8565.

59. Stremlau, M.; Perron, M.; Welikala, S.; Sodroski, J. Species-specific variation in the B30.2(SPRY) domain of TRIM5alpha determines the potency of human immunodeficiency virus restriction. J. Virol. 2005, 79, 3139-3145.

60. Javanbakht, H.; Yuan, W.; Yeung, D.F.; Song, B.; Diaz-Griffero, F.; Li, Y.; Li, X.; Stremlau, M.; Sodroski, J. Characterization of TRIM5alpha trimerization and its contribution to human immunodeficiency virus capsid binding. Virology 2006, 353, 234-246.

61. Yap, M.W.; Nisole, S.; Stoye, J.P. A single amino acid change in the SPRY domain of human Trim5alpha leads to HIV-1 restriction. Curr. Biol. 2005, 15, 73-78.

62. Sastri, J.; Campbell, E.M. Recent insights into the mechanism and consequences of TRIM5alpha retroviral restriction. AIDS Res. Hum. Retroviruses 2011, 27, 231-238.

63. Perron, M.J.; Stremlau, M.; Lee, M.; Javanbakht, H.; Song, B.; Sodroski, J. The human TRIM5alpha restriction factor mediates accelerated uncoating of the N-tropic murine leukemia virus capsid. J. Virol. 2007, 81, 2138-2148.

64. Stremlau, M.; Perron, M.; Lee, M.; Li, Y.; Song, B.; Javanbakht, H.; Diaz-Griffero, F.; Anderson, D.J.; Sundquist, W.I.; Sodroski, J. Specific recognition and accelerated uncoating of retroviral capsids by the TRIM5alpha restriction factor. Proc. Natl. Acad. Sci. U. S. A. 2006, 103, 5514-5519.

65. Münk, C.; Brandt, S.M.; Lucero, G.; Landau, N.R. A dominant block to HIV-1 replication at reverse transcription in simian cells. Proc. Natl. Acad. Sci. U. S. A. 2002, 99, 13843-13848.

66. Wu, X.; Anderson, J.L.; Campbell, E.M.; Joseph, A.M.; Hope, T.J. Proteasome inhibitors uncouple rhesus TRIM5alpha restriction of HIV-1 reverse transcription and infection. Proc. Natl. Acad. Sci. U. S. A. 2006, 103, 7465-7470.

67. Pertel, T.; Hausmann, S.; Morger, D.; Zuger, S.; Guerra, J.; Lascano, J.; Reinhard, C.; Santoni, F.A.; Uchil, P.D.; Chatel, L.; et al. TRIM5 is an innate immune sensor for the retrovirus capsid lattice. Nature 2011, 472, 361-365.

68. Saenz, D.T.; Teo, W.; Olsen, J.C.; Poeschla, E.M. Restriction of feline immunodeficiency virus by Ref1, Lv1, and primate TRIM5alpha proteins. J. Virol. 2005, 79, 15175-15188.

69. Brennan, G.; Kozyrev, Y.; Hu, S.L. TRIMCyp expression in Old World primates Macaca nemestrina and Macaca fascicularis. Proc. Natl. Acad. Sci. U. S. A. 2008, 105, 3569-3574.

70. Newman, R.M.; Hall, L.; Kirmaier, A.; Pozzi, L.A.; Pery, E.; Farzan, M.; O'Neil, S.P.; Johnson, W. Evolution of a TRIM5-CypA splice isoform in old world monkeys. PLoS Pathog. 2008, 4, e1000003.

71. Sayah, D.M.; Sokolskaja, E.; Berthoux, L.; Luban, J. Cyclophilin A retrotransposition into TRIM5 explains owl monkey resistance to HIV-1. Nature 2004, 430, 569-573.

72. Virgen, C.A.; Kratovac, Z.; Bieniasz, P.D.; Hatziioannou, T. Independent genesis of chimeric TRIM5-cyclophilin proteins in two primate species. Proc. Natl. Acad. Sci. U. S. A. 2008, 105, 3563-3568. 
73. Wilson, S.J.; Webb, B.L.; Ylinen, L.M.; Verschoor, E.; Heeney, J.L.; Towers, G.J. Independent evolution of an antiviral TRIMCyp in rhesus macaques. Proc. Natl. Acad. Sci. U. S. A. 2008, 105, 3557-3562.

74. Nisole, S.; Lynch, C.; Stoye, J.P.; Yap, M.W. A Trim5-cyclophilin A fusion protein found in owl monkey kidney cells can restrict HIV-1. Proc. Natl. Acad. Sci. U. S. A. 2004, 101, 13324-13328.

75. Dietrich, I.; Macintyre, A.; McMonagle, E.; Price, A.J.; James, L.C.; McEwan, W.A.; Hosie, M.J.; Willett, B.J. Potent lentiviral restriction by a synthetic feline TRIM5 cyclophilin A fusion. J. Virol. 2010, 84, 8980-8985.

76. Gamble, T.R.; Vajdos, F.F.; Yoo, S.; Worthylake, D.K.; Houseweart, M.; Sundquist, W.I.; Hill, C.P. Crystal structure of human cyclophilin A bound to the amino-terminal domain of HIV-1 capsid. Cell 1996, 87, 1285-1294.

77. Luban, J.; Bossolt, K.L.; Franke, E.K.; Kalpana, G.V.; Goff, S.P. Human immunodeficiency virus type 1 Gag protein binds to cyclophilins A and B. Cell 1993, 73, 1067-1078.

78. Lin, T.Y.; Emerman, M. Cyclophilin A interacts with diverse lentiviral capsids. Retrovirology 2006, 3, 70 .

79. Diaz-Griffero, F.; Vandegraaff, N.; Li, Y.; McGee-Estrada, K.; Stremlau, M.; Welikala, S.; Si, Z.; Engelman, A.; Sodroski, J. Requirements for capsid-binding and an effector function in TRIMCyp-mediated restriction of HIV-1. Virology 2006, 351, 404-419.

80. Neagu, M.R.; Ziegler, P.; Pertel, T.; Strambio-De-Castillia, C.; Grutter, C.; Martinetti, G.; Mazzucchelli, L.; Grutter, M.; Manz, M.G.; Luban, J. Potent inhibition of HIV-1 by TRIM5cyclophilin fusion proteins engineered from human components. J. Clin. Invest 2009, 119, 3035-3047.

81. Dietrich, E.A.; Brennan, G.; Ferguson, B.; Wiseman, R.W.; O'Connor, D.; Hu, S.L. Variable prevalence and functional diversity of the antiretroviral restriction factor TRIMCyp in Macaca fascicularis. J. Virol. 2011, 85, 9956-9963.

82. Wongsrikeao, P.; Saenz, D.; Rinkoski, T.; Otoi, T.; Poeschla, E. Antiviral restriction factor transgenesis in the domestic cat. Nat. Methods 2011, 8, 853-859.

83. Dietrich, I.; McMonagle, E.L.; Petit, S.J.; Vijayakrishnan, S.; Logan, N.; Chan, C.N.; Towers, G.J.; Hosie, M.J.; Willett, B.J. Feline tetherin efficiently restricts release of feline immunodeficiency virus but not spreading of infection. J. Virol. 2011, 85, 5840-5852.

84. Neil, S.J.; Zang, T.; Bieniasz, P.D. Tetherin inhibits retrovirus release and is antagonized by HIV-1 Vpu. Nature 2008, 451, 425-430.

85. Van, D.N.; Goff, D.; Katsura, C.; Jorgenson, R.L.; Mitchell, R.; Johnson, M.C.; Stephens, E.B.; Guatelli, J. The interferon-induced protein BST-2 restricts HIV-1 release and is downregulated from the cell surface by the viral Vpu protein. Cell Host Microbe 2008, 3, 245-252.

86. Mitchell, R.S.; Katsura, C.; Skasko, M.A.; Fitzpatrick, K.; Lau, D.; Ruiz, A.; Stephens, E.B.; Margottin-Goguet, F.; Benarous, R.; Guatelli, J.C. Vpu antagonizes BST-2-mediated restriction of HIV-1 release via beta-TrCP and endo-lysosomal trafficking. PLoS Pathog. 2009, 5, e1000450.

87. Douglas, J.L.; Viswanathan, K.; McCarroll, M.N.; Gustin, J.K.; Fruh, K.; Moses, A.V. Vpu directs the degradation of the human immunodeficiency virus restriction factor BST-2/Tetherin via a $\{$ beta\} TrCP-dependent mechanism. J. Virol. 2009, 83, 7931-7947. 
88. Douglas, J.L.; Gustin, J.K.; Viswanathan, K.; Mansouri, M.; Moses, A.V.; Fruh, K. The great escape: Viral strategies to counter BST-2/tetherin. PLoS Pathog. 2010, 6, e1000913.

89. Evans, D.T.; Serra-Moreno, R.; Singh, R.K.; Guatelli, J.C. BST-2/tetherin: A new component of the innate immune response to enveloped viruses. Trends Microbiol. 2010, 18, 388-396.

90. Kuhl, B.D.; Cheng, V.; Wainberg, M.A.; Liang, C. Tetherin and its viral antagonists. J. Neuroimmune. Pharmacol. 2011, 6, 188-201.

91. Jouvenet, N.; Neil, S.J.; Zhadina, M.; Zang, T.; Kratovac, Z.; Lee, Y.; McNatt, M.; Hatziioannou, T.; Bieniasz, P.D. Broad-spectrum inhibition of retroviral and filoviral particle release by tetherin. J. Virol. 2009, 83, 1837-1844.

92. Kaletsky, R.L.; Francica, J.R.; Agrawal-Gamse, C.; Bates, P. Tetherin-mediated restriction of filovirus budding is antagonized by the Ebola glycoprotein. Proc. Natl. Acad. Sci. U. S. A. 2009, 106, 2886-2891.

93. Mansouri, M.; Viswanathan, K.; Douglas, J.L.; Hines, J.; Gustin, J.; Moses, A.V.; Fruh, K. Molecular mechanism of BST2/tetherin downregulation by K5/MIR2 of Kaposi's sarcomaassociated herpesvirus. J. Virol. 2009, 83, 9672-9681.

94. Sakuma, T.; Noda, T.; Urata, S.; Kawaoka, Y.; Yasuda, J. Inhibition of Lassa and Marburg virus production by tetherin. J. Virol. 2009, 83, 2382-2385.

95. Radoshitzky, S.R.; Dong, L.; Chi, X.; Clester, J.C.; Retterer, C.; Spurgers, K.; Kuhn, J.H.; Sandwick, S.; Ruthel, G.; Kota, K.; et al. Infectious Lassa virus, but not filoviruses, is restricted by BST-2/tetherin. J. Virol. 2010, 84, 10569-10580.

96. Weidner, J.M.; Jiang, D.; Pan, X.B.; Chang, J.; Block, T.M.; Guo, J.T. Interferon-induced cell membrane proteins, IFITM3 and tetherin, inhibit vesicular stomatitis virus infection via distinct mechanisms. J. Virol. 2010, 84, 12646-12657.

97. Yondola, M.A.; Fernandes, F.; Belicha-Villanueva, A.; Uccelini, M.; Gao, Q.; Carter, C.; Palese, P. Budding capability of the influenza virus neuraminidase can be modulated by tetherin. J. Virol. 2011, 85, 2480-2491.

98. Watanabe, R.; Leser, G.P.; Lamb, R.A. Influenza virus is not restricted by tetherin whereas influenza VLP production is restricted by tetherin. Virology 2011, 417, 50-56.

99. Kupzig, S.; Korolchuk, V.; Rollason, R.; Sugden, A.; Wilde, A.; Banting, G. Bst-2/HM1.24 is a raft-associated apical membrane protein with an unusual topology. Traffic 2003, 4, 694-709.

100. Andrew, A.J.; Kao, S.; Strebel, K. The C-terminal hydrophobic region in human BST-2/tetherin functions as a second transmembrane motif. J. Biol. Chem. 2011, doi:10.1074/jbc.M111.287011.

101. Erikson, E.; Adam, T.; Schmidt, S.; Lehmann-Koch, J.; Over, B.; Goffinet, C.; Harter, C.; Bekeredjian-Ding, I.; Sertel, S.; Lasitschka, F.; et al. In vivo expression profile of the antiviral restriction factor and tumor-targeting antigen CD317/BST-2/HM1.24/tetherin in humans. Proc. Natl. Acad. Sci. U. S. A. 2011, 108, 13688-13693.

102. Fukuma, A.; Abe, M.; Morikawa, Y.; Miyazawa, T.; Yasuda, J. Cloning and characterization of the antiviral activity of feline Tetherin/BST-2. PLoS One 2011, 6, e18247.

103. Jolly, C.; Booth, N.J.; Neil, S.J. Cell-cell spread of human immunodeficiency virus type 1 overcomes tetherin/BST-2-mediated restriction in T cells. J. Virol. 2010, 84, 12185-12199. 
104. Casartelli, N.; Sourisseau, M.; Feldmann, J.; Guivel-Benhassine, F.; Mallet, A.; Marcelin, A.G.; Guatelli, J.; Schwartz, O. Tetherin restricts productive HIV-1 cell-to-cell transmission. PLoS Pathog. 2010, 6, e1000955.

105. Sauter, D.; Schindler, M.; Specht, A.; Landford, W.N.; Munch, J.; Kim, K.A.; Votteler, J.; Schubert, U.; Bibollet-Ruche, F.; Keele, B.F.; et al. Tetherin-driven adaptation of Vpu and Nef function and the evolution of pandemic and nonpandemic HIV-1 strains. Cell Host Microbe 2009, $6,409-421$.

106. Collman, R.; Hassan, N.F.; Walker, R.; Godfrey, B.; Cutilli, J.; Hastings, J.C.; Friedman, H.; Douglas, S.D.; Nathanson, N. Infection of monocyte-derived macrophages with human immunodeficiency virus type 1 (HIV-1). Monocyte-tropic and lymphocyte-tropic strains of HIV-1 show distinctive patterns of replication in a panel of cell types. J. Exp. Med. 1989, 170, 1149-1163.

107. Mühlebach, M.D.; Wolfrum, N.; Schule, S.; Tschulena, U.; Sanzenbacher, R.; Flory, E.; Cichutek, K.; Schweizer, M. Stable transduction of primary human monocytes by simian lentiviral vector PBj. Mol. Ther. 2005, 12, 1206-1216.

108. Naif, H.M.; Li, S.; Alali, M.; Sloane, A.; Wu, L.; Kelly, M.; Lynch, G.; Lloyd, A.; Cunningham, A.L. CCR5 expression correlates with susceptibility of maturing monocytes to human immunodeficiency virus type 1 infection. J. Virol. 1998, 72, 830-836.

109. Neil, S.; Martin, F.; Ikeda, Y.; Collins, M. Postentry restriction to human immunodeficiency virus-based vector transduction in human monocytes. J. Virol. 2001, 75, 5448-5456.

110. Rich, E.A.; Chen, I.S.; Zack, J.A.; Leonard, M.L.; O'Brien, W.A. Increased susceptibility of differentiated mononuclear phagocytes to productive infection with human immunodeficiency virus-1 (HIV-1). J. Clin. Invest 1992, 89, 176-183.

111. Sonza, S.; Maerz, A.; Deacon, N.; Meanger, J.; Mills, J.; Crowe, S. Human immunodeficiency virus type 1 replication is blocked prior to reverse transcription and integration in freshly isolated peripheral blood monocytes. J. Virol. 1996, 70, 3863-3869.

112. Ayinde, D.; Maudet, C.; Transy, C.; Margottin-Goguet, F. Limelight on two HIV/SIV accessory proteins in macrophage infection: Is Vpx overshadowing Vpr? Retrovirology. 2010, 7, 35.

113. Sprague, W.S.; Robbiani, M.; Avery, P.R.; O'Halloran, K.P.; Hoover, E.A. Feline immunodeficiency virus dendritic cell infection and transfer. J. Gen. Virol. 2008, 89, 709-715.

114. van der Meer, F.J.; Schuurman, N.M.; Egberink, H.F. Feline immunodeficiency virus infection is enhanced by feline bone marrow-derived dendritic cells. J. Gen. Virol. 2007, 88, 251-258.

115. Goujon, C.; Riviere, L.; Jarrosson-Wuilleme, L.; Bernaud, J.; Rigal, D.; Darlix, J.L.; Cimarelli, A. SIVSM/HIV-2 Vpx proteins promote retroviral escape from a proteasome-dependent restriction pathway present in human dendritic cells. Retrovirology 2007, 4, 2.

116. Henderson, L.E.; Sowder, R.C.; Copeland, T.D.; Benveniste, R.E.; Oroszlan, S. Isolation and characterization of a novel protein (X-ORF product) from SIV and HIV-2. Science 1988, 241, 199-201.

117. Horton, R.; Spearman, P.; Ratner, L. HIV-2 viral protein X association with the GAG p27 capsid protein. Virology 1994, 199, 453-457. 
118. Guyader, M.; Emerman, M.; Montagnier, L.; Peden, K. VPX mutants of HIV-2 are infectious in established cell lines but display a severe defect in peripheral blood lymphocytes. EMBO J. 1989, 8, 1169-1175.

119. Yu, X.F.; Yu, Q.C.; Essex, M.; Lee, T.H. The vpx gene of simian immunodeficiency virus facilitates efficient viral replication in fresh lymphocytes and macrophage. J. Virol. 1991, 65, 5088-5091.

120. Gibbs, J.S.; Regier, D.A.; Desrosiers, R.C. Construction and in vitro properties of SIVmac mutants with deletions in "nonessential" genes. AIDS Res. Hum. Retroviruses 1994, 10, 607-616.

121. Hirsch, V.M.; Sharkey, M.E.; Brown, C.R.; Brichacek, B.; Goldstein, S.; Wakefield, J.; Byrum, R.; Elkins, W.R.; Hahn, B.H.; Lifson, J.D.; et al. Vpx is required for dissemination and pathogenesis of SIV(SM) PBj: Evidence of macrophage-dependent viral amplification. Nat. Med. 1998, 4, 1401-1408.

122. Gibbs, J.S.; Lackner, A.A.; Lang, S.M.; Simon, M.A.; Sehgal, P.K.; Daniel, M.D.; Desrosiers, R.C. Progression to AIDS in the absence of a gene for vpr or vpx. J. Virol. 1995, 69, 2378-2383.

123. Fujita, M.; Otsuka, M.; Miyoshi, M.; Khamsri, B.; Nomaguchi, M.; Adachi, A. Vpx is critical for reverse transcription of the human immunodeficiency virus type 2 genome in macrophages. J. Virol. 2008, 82, 7752-7756.

124. Gramberg, T.; Sunseri, N.; Landau, N.R. Evidence for an activation domain at the amino terminus of simian immunodeficiency virus Vpx. J. Virol. 2010, 84, 1387-1396.

125. Srivastava, S.; Swanson, S.K.; Manel, N.; Florens, L.; Washburn, M.P.; Skowronski, J. Lentiviral Vpx accessory factor targets VprBP/DCAF1 substrate adaptor for cullin 4 E3 ubiquitin ligase to enable macrophage infection. PLoS Pathog. 2008, 4, e1000059.

126. Hrecka, K.; Hao, C.; Gierszewska, M.; Swanson, S.K.; Kesik-Brodacka, M.; Srivastava, S.; Florens, L.; Washburn, M.P.; Skowronski, J. Vpx relieves inhibition of HIV-1 infection of macrophages mediated by the SAMHD1 protein. Nature 2011, 474, 658-661.

127. Laguette, N.; Sobhian, B.; Casartelli, N.; Ringeard, M.; Chable-Bessia, C.; Segeral, E.; Yatim, A.; Emiliani, S.; Schwartz, O.; Benkirane, M. SAMHD1 is the dendritic- and myeloid-cell-specific HIV-1 restriction factor counteracted by Vpx. Nature 2011, 474, 654-657.

128. Qiao, F.; Bowie, J.U. The many faces of SAM. Sci. STKE. 2005, 2005 , re7.

129. Aravind, L.; Koonin, E.V. The HD domain defines a new superfamily of metal-dependent phosphohydrolases. Trends Biochem. Sci. 1998, 23, 469-472.

130. Rice, G.I.; Bond, J.; Asipu, A.; Brunette, R.L.; Manfield, I.W.; Carr, I.M.; Fuller, J.C.; Jackson, R.M.; Lamb, T.; Briggs, T.A.; et al. Mutations involved in Aicardi-Goutieres syndrome implicate SAMHD1 as regulator of the innate immune response. Nat. Genet. 2009, 41, 829-832.

131. Gao, F.; Bailes, E.; Robertson, D.L.; Chen, Y.; Rodenburg, C.M.; Michael, S.F.; Cummins, L.B.; Arthur, L.O.; Peeters, M.; Shaw, G.M.; et al. Origin of HIV-1 in the chimpanzee Pan troglodytes troglodytes. Nature 1999, 397, 436-441.

132. Hirsch, V.M.; Olmsted, R.A.; Murphey-Corb, M.; Purcell, R.H.; Johnson, P.R. An African primate lentivirus (SIVsm) closely related to HIV-2. Nature 1989, 339, 389-392.

133. Lemey, P.; Pybus, O.G.; Wang, B.; Saksena, N.K.; Salemi, M.; Vandamme, A.M. Tracing the origin and history of the HIV-2 epidemic. Proc. Natl. Acad. Sci. U. S. A. 2003, 100, 6588-6592. 
134. Tomonaga, K.; Miyazawa, T.; Sakuragi, J.; Mori, T.; Adachi, A.; Mikami, T. The feline immunodeficiency virus ORF-A gene facilitates efficient viral replication in established T-cell lines and peripheral blood lymphocytes. J. Virol. 1993, 67, 5889-5895.

135. Pistello, M.; Moscardini, M.; Mazzetti, P.; Bonci, F.; Zaccaro, L.; Isola, P.; Freer, G.; Specter, S.; Matteucci, D.; Bendinelli, M. Development of feline immunodeficiency virus ORF-A (tat) mutants: In vitro and in vivo characterization. Virology 2002, 298, 84-95.

136. Chatterji, U.; de, P.A.; Elder, J.H. Feline immunodeficiency virus OrfA is distinct from other lentivirus transactivators. J. Virol. 2002, 76, 9624-9634.

137. Gemeniano, M.C.; Sawai, E.T.; Leutenegger, C.M.; Sparger, E.E. Feline immunodeficiency virus ORF-Ais required for virus particle formation and virus infectivity. J. Virol. 2003, 77, 8819-8830.

138. Gemeniano, M.C.; Sawai, E.T.; Sparger, E.E. Feline immunodeficiency virus Orf-A localizes to the nucleus and induces cell cycle arrest. Virology 2004, 325, 167-174.

139. Hong, Y.; Fink, E.; Hu, Q.Y.; Kiosses, W.B.; Elder, J.H. OrfA downregulates feline immunodeficiency virus primary receptor CD134 on the host cell surface and is important in viral infection. J. Virol. 2010, 84, 7225-7232.

140. Robert-Tissot, C.; Ruegger, V.L.; Cattori, V.; Meli, M.L.; Riond, B.; Gomes-Keller, M.A.; Vogtlin, A.; Wittig, B.; Juhls, C.; Hofmann-Lehmann, R.; et al. The innate antiviral immune system of the cat: Molecular tools for the measurement of its state of activation. Vet. Immunol. Immunopathol. 2011, 143, 269-281.

141. Schrofelbauer, B.; Hakata, Y.; Landau, N.R. HIV-1 Vpr function is mediated by interaction with the damage-specific DNA-binding protein DDB1. Proc. Natl. Acad. Sci. U. S. A. 2007, 104, 4130-4135.

142. Gallois-Montbrun, S.; Kramer, B.; Swanson, C.M.; Byers, H.; Lynham, S.; Ward, M.; Malim, M.H. Antiviral protein APOBEC3G localizes to ribonucleoprotein complexes found in P bodies and stress granules. J. Virol. 2007, 81, 2165-2178.

143. Mitchell, R.S.; Katsura, C.; Skasko, M.A.; Fitzpatrick, K.; Lau, D.; Ruiz, A.; Stephens, E.B.; Margottin-Goguet, F.; Benarous, R.; Guatelli, J.C. Vpu antagonizes BST-2-mediated restriction of HIV-1 release via beta-TrCP and endo-lysosomal trafficking. PLoS Pathog. 2009, 5, e1000450.

(C) 2011 by the authors; licensee MDPI, Basel, Switzerland. This article is an open access article distributed under the terms and conditions of the Creative Commons Attribution license (http://creativecommons.org/licenses/by/3.0/). 